\title{
YAP activation attenuates toxicarioside G-induced lethal autophagy arrest in SW480 colorectal cancer cells
}

\author{
LIMIN ZHOU $^{1,2^{*}}$, JINYAN WANG $^{1 *}$, JIAQI LIU $^{1}$, JIANTANG LIANG $^{1}$, \\ YANSONG WANG ${ }^{3}$, QUNFANG CAI ${ }^{4}$ and YONGHAO HUANG ${ }^{1,5}$
}

\author{
${ }^{1}$ Key Laboratory of Tropical Translational Medicine of The Ministry of Education and Hainan Provincial Key Laboratory of \\ Tropical Medicine, Hainan Medical University; ${ }^{2}$ Public Research Laboratory, Hainan Medical University; \\ ${ }^{3}$ Hainan Haitai Biomedical Technology Co., Ltd.; ${ }^{4}$ School of Tropical Medicine and Laboratory Medicine, \\ Hainan Medical University; ${ }^{5}$ Department of Anesthesiology, Second Affiliated Hospital, \\ Hainan Medical University, Haikou, Hainan 571199, P.R. China
}

Received April 17, 2021; Accepted July 29, 2021

DOI: $10.3892 /$ or.2021.8175

\begin{abstract}
Toxicarioside G (TCG), a natural product isolated from Calotropis gigantea, has been found to exhibit potent anticancer effects. The present study aimed to investigate the effect of TCG on the SW480 colorectal cancer cell line and the role of autophagy and Yes1 associated transcriptional regulator (YAP) in the TCG-mediated inhibition of cell proliferation and viability. Cell proliferation was detected using MTT, BrdU, colony formation and LDH release assays, while apoptosis was analyzed using flow cytometry and western blot analyses. Immunofluorescence and western blot analysis was used to determine TCG-induced autophagy and YAP activation. Pharmacological inhibition and siRNA was used to investigate the role of autophagy and YAP in TCG-mediated cell growth inhibition. The results revealed that TCG inhibited SW480 cell proliferation and viability, independent of apoptosis, and also induced autophagy. It was further demonstrated that TCG blocks autophagic flux, resulting in autophagy arrest in the SW480 cell line. The inhibition of autophagy restored the TCG-mediated inhibition of cell proliferation and viability, suggesting that TCG may induce lethal autophagy arrest in the SW480 cell line. Furthermore, TCG induced YAP
\end{abstract}

Correspondence to: Mrs Qunfang Cai, School of Tropical Medicine and Laboratory Medicine, Hainan Medical University, 3 Xueyuan Road, Haikou, Hainan 571199, P.R. China

E-mail: 450088470@qq.com

Dr Yonghao Huang, Key Laboratory of Tropical Translational Medicine of The Ministry of Education and Hainan Provincial Key Laboratory of Tropical Medicine, Hainan Medical University, 3 Xueyuan Road, Haikou, Hainan 571199, P.R. China

E-mail: hyh802110@163.com

*Contributed equally

Key words: toxicarioside G, autophagy arrest, Yes1 associated transcriptional regulator, cell proliferation, colorectal cancer cells activation in the SW480 cell line. Inhibition of YAP activity enhanced the TCG-mediated inhibition of cell proliferation and viability, suggesting that YAP may play a protective role in the TCG-induced effects. In conclusion, the findings of the present study indicated that TCG may induce lethal autophagy arrest and activate YAP, which serves a protective role in the SW480 cell line. These results suggested that the combined targeting of TCG and YAP may represent a promising strategy for TCG-mediated anticancer therapy.

\section{Introduction}

Toxicarioside G (TCG) is a cardenolide isolated from Calotropis gigantean. Apart from their traditional use in the treatment of congestive heart failure and arrhythmia, cardenolides have recently been proven to exert potent anticancer activities (1-5). Previous studies have demonstrated that other cardenolides isolated from Calotropis gigantean exhibited significant cytotoxicity against numerous types of human cancer cells, such as hepatoma carcinoma, gastric cancer and lung cancer (6-8). Consistent with these observations, TCG has been found to exert significant anticancer effects in various cancer cell types, such as hepatoma carcinoma, gastric cancer and cervical cancer cell lines (6). However, to the best of our knowledge, the underlying mechanisms by which TCG inhibits tumor growth remains poorly understood.

Autophagy is a conserved catabolic process whereby aggregated proteins or damaged organelles are sequestered by double-membrane autophagosomes and degraded in autolysosomes, which maintains cellular homeostasis under physiological conditions $(9,10)$. Induction of autophagy has been observed in various types of cancer cells challenged with intra- and extracellular stresses; however, the role of autophagy in regulating the fate of cancer cells remains controversial (11-13). On the one hand, inhibition of autophagy was discovered to promote cell death or chemosensitivity, suggesting that autophagy is required for cancer progression $(14,15)$. On the other hand, activation of autophagy has been found to inhibit cell proliferation or cell death, indicating that autophagy may play a tumor-suppressive role $(16,17)$. Therefore, understanding the role of autophagy 
and the related mechanisms in cancer cells is important for enhancing the effectiveness of cancer treatment.

The Hippo signaling pathway is an evolutionarily conserved pathway that controls organ size and tissue homeostasis $(18,19)$. In recent years, the Hippo signaling pathway has emerged as a key regulator in cancer development and progression (20). The kinase cascade of Mst1/2 and large tumor suppressor kinase $1 / 2$ (LATS1/2) represents a core component of the mammalian Hippo signaling pathway (21). When the Hippo pathway is activated by upstream signals, Mst1/2 phosphorylates and activates LATS1/2, which subsequently phosphorylates Yes1 associated transcriptional regulator (YAP). This phosphorylation event retains YAP in the cytoplasm, which prevents YAP from being translocated into the nucleus to interact with the TEA domain transcription factor 1 family of transcription factors and activate its downstream genes, such as cellular communication network factor 2 (CTGF) and cellular communication network factor 1 (CCN1) $(22,23)$. As a key downstream effector of the Hippo signaling pathway, YAP has been discovered to play important roles in cell proliferation and the survival of cancer cells. YAP amplification has been frequently observed in a large number of human cancer types, including in lung, liver, colon and gastric cancers $(19,24)$. In addition, the abnormal activation of YAP was found to be associated with the progression of numerous types of cancer, such as lun, colorectal and lover cancer suggesting that YAP may play an important role in tumorigenesis (24-26).

The aim of the present study was to investigate the effect of TCG on the SW480 colorectal cancer cell and determine whether autophagy and Yes1 associated transcriptional regulator (YAP) were associated with TCG-mediated inhibition of cell proliferation and viability.

\section{Materials and methods}

Cell culture and reagents. The human colorectal cancer cell lines, SW480 and HT-29, were purchased from the American Type Culture Collection. The cells were cultured in RPMI-1640 medium (Gibco; Thermo Fisher Scientific, Inc.) supplemented with 10\% FBS (Gibco; Thermo Fisher Scientific, Inc.) and 1\% penicillin/streptomycin (Sigma-Aldrich; Merck KGaA), and maintained at $37^{\circ} \mathrm{C}$ in a humidified incubator with $5 \% \mathrm{CO}_{2}$. The cells were treated with TCG (purity, $\geq 95 \%$ ), which was kindly gifted by Professor HaoFu Dai (Chinese Academy of Tropical Agricultural Sciences, Haikou, China).

The PI3K inhibitor, 3-methyladenine (3-MA; cat. no. 189490) and chloroquine (CQ; cat. no. C6628) were purchased from Sigma-Aldrich (Merck KGaA). Verteporfin (VP; cat. no. HY-B0146) was purchased from MedChemExpress. The cells were treated with $10 \mathrm{mM} 3-\mathrm{MA}$, $5 \mu \mathrm{M} \mathrm{CQ}$, or $10 \mu \mathrm{M} \mathrm{VP}$ at $37^{\circ} \mathrm{C}$ for $24 \mathrm{~h}$.

Cytotoxicity assay. Cell cytotoxicity was measured using a MTT assay. Briefly, SW480 or HT-29 cells were seeded (1) $10^{6} /$ well) into 96-well plates and treated with indicated concentrations of TCG or DMSO (or $10 \mathrm{mM} 3-\mathrm{MA}, 5 \mu \mathrm{M}$ CQ and $10 \mu \mathrm{M} \mathrm{VP}$ ) for $24 \mathrm{~h}$ at $37^{\circ} \mathrm{C}$. Following incubation, $10 \mu \mathrm{l}$ MTT was added to each well and the samples were incubated for a further $4 \mathrm{~h}$ at $37^{\circ} \mathrm{C}$. Then, $200 \mu \mathrm{l}$ DMSO was added to each well to dissolve purple formazan. The absorbance was measured at $570 \mathrm{~nm}$ using an ELISA reader (Bio-Rad Laboratories, Inc.).

Bromodeoxyuridine (BrdU) incorporation assay. The SW480 cells were seeded (1x10\% $/$ well) into 96-well plates and treated with indicated concentrations of TCG or DMSO (or $10 \mathrm{mM}$ 3-MA and $10 \mu \mathrm{M} \mathrm{VP}$ ) for $24 \mathrm{~h}$. Following incubation, cell proliferation was determined using a BrdU Cell Proliferation ELISA kit (cat. no. ab126556; Abcam) according to the manufacturer's protocol.

Colony formation assay. The SW480 cells were seeded (1x10 $/$ well) into 24 -well plates and treated with indicated concentrations of TCG or DMSO (or 3-MA according to each experiment requires). Following 7 days of incubation, the colonies were stained with Giemsa for $15 \mathrm{~min}$ at $37^{\circ} \mathrm{C}$, then washed three times with PBS. The visible colonies were visualized using a Molecular Imager Gel Do XR+ system (Bio-Rad Laboratories, Inc.) and counted using ImageJ 1.47 software (National Institutes of Health).

Lactate dehydrogenase $(\mathrm{LDH})$ release assay. The SW480 cells were seeded (1x10\% $/$ well) into 96-well plates and treated with indicated concentrations of TCG or DMSO (or $10 \mathrm{mM}$ 3-MA and $10 \mu \mathrm{M} \mathrm{VP}$ ) for $24 \mathrm{~h}$. Following incubation, the cytotoxicity was measured using a LDH release kit (cat. no. C0016; Beyotime Institute of Biotechnology) according to the manufacturer's protocol.

Flow cytometry. Briefly, the SW480 cells were seeded (3x105/well) into 6 -well plates and treated with TCG $(0$, 0.2 and $0.4 \mu \mathrm{M}$ ) for $24 \mathrm{~h}$. Following incubation, the cells were harvested and washed with PBS, then resuspended in PI/AnnexinV solution (Nanjing KeyGen Biotech Co., Ltd.). Apoptosis was subsequently analyzed using a FACSCalibur flow cytometer (BD Biosciences) and FlowJo v7.6.1 software (FlowJo LLC).

Western blot analysis. Total protein was extracted from the SW480 cells treated with $0,0.2$ and $0.4 \mu \mathrm{M}$ TCG (or control, $0.4 \mu \mathrm{M}$ TCG, $10 \mathrm{mM}$ 3-MA, $0.4 \mu \mathrm{M}$ TCG+10 mM 3-MA; or control, $0.4 \mu \mathrm{M}$ TCG, $5 \mu \mathrm{M} \mathrm{CQ}, 0.4 \mu \mathrm{M}$ TCG+5 $\mu \mathrm{M}$ CQ) using RIPA lysis buffer (Thermo Fisher Scientific, Inc.) and quantified using a BCA protein assay kit (Thermo Fisher Scientific, Inc.). The proteins were separated using 10\% SDS-PAGE and transferred onto PVDF membranes. After blocking with 5\% BSA (Sigma-Aldrich; Merck KGaA) for $30 \mathrm{~min}$ at $37^{\circ} \mathrm{C}$, the membranes were incubated at $4^{\circ} \mathrm{C}$ overnight with the following primary antibodies: Anti-poly (ADP-ribose) polymerase 1 (PARP; cat. no. ab191217; 1:1,000; Abcam), anti-caspase-3 (cat. no. ab32351; 1:1,000; Abcam), anti-LC3B (cat. no. L7543; 1:2,000; Sigma-Aldrich; Merck KGaA), anti-Beclin1 (cat. no. ab210498; 1:1,000; Abcam), anti-autophagy related 5 (ATG5; cat. no. ab108327; 1:1,000; Abcam), anti-P62 (cat. no. ab109012; 1:1,000; Abcam), anti-phosphorylated (p)-YAP (cat. no. ab76252; 1:1,000; Abcam), anti-YAP (cat. no. ab52771; 1:1,000; Abcam), anti-LATS1 (cat. no. 3477; 1:1,000; Cell Signaling Technology, Inc.) and anti- $\beta$-actin (cat. no. ab8226; 1:2,000; Abcam). Following incubation with 
the primary antibodies, the membranes were incubated with secondary antibodies (anti-rabbit IgG; cat. no. ab6721; 1:2,000; Abcam) at room temperature for $2 \mathrm{~h}$. The protein bands were visualized using an enhanced chemiluminescence reagent (cat. no. WBKLS0100; MilliporeSigma) and the protein ratios were calculated following densitometric analysis using ImageJ v1.47 software (National Institutes of Health).

Reverse transcription-quantitative PCR (RT-qPCR). Total RNA was extracted from the SW480 cells using TRIzol ${ }^{\circledR}$ (Invitrogen; Thermo Fisher Scientific, Inc.). Total RNA was reverse transcribed into cDNA using reverse transcriptase and random hexamers from a RevertAid First Strand cDNA Synthesis kit (Thermo Fisher Scientific, Inc.). The following temperature protocol was used: Priming at $25^{\circ} \mathrm{C}$ for $5 \mathrm{~min}$, RT at $42^{\circ} \mathrm{C}$ for $60 \mathrm{~min}$, then inactivation at $70^{\circ} \mathrm{C}$ for $5 \mathrm{~min}$. qPCR was subsequently performed by mixing cDNA, gene-specific primers and IQ SYRB Green Supermix (Agilent Technologies, Inc.) and detected using a Mx3005P Real-Time PCR system (Agilent Technologies, Inc.) according to the manufacturer's protocol. The following primers were used for the qPCR: CTGF forward, 5'-AAAAGTGCATCCGTACTCCCA-3' and reverse, 5'-CCG TCGGTACATACTCCACAG-3'; CCN1 forward, 5'-AGCCTC GCATCCTATACAACC-3' and reverse, 5'-TTCTTTCAC AAGGCGGCACTC-3'; and GAPDH forward, 5'-GAGCGA GATCCCTCCAAAAT-3' and reverse, 5'-GGCTGTTGTCAT ACTTCTCATGG-3'. The following thermocycling conditions were used for qPCR: Initial denaturation at $95^{\circ} \mathrm{C}$ for $2 \mathrm{~min}$, followed by 40 cycles of denaturation at $94^{\circ} \mathrm{C}$ for $15 \mathrm{sec}$, and annealing/extension at $60^{\circ} \mathrm{C}$ for $1 \mathrm{~min}$. Expression levels were quantified using the $2^{-\Delta \Delta \mathrm{Cq}}$ method and fold changes were obtained by normalization to GAPDH expression (27).

Immunofluorescence assay. The SW480 cells treated with $0.4 \mu \mathrm{M}$ TCG or control (or $5 \mu \mathrm{M} \mathrm{CQ}$ ) were fixed with $4 \%$ paraformaldehyde at room temperature for $30 \mathrm{~min}$, washed with PBS, then incubated with $0.1 \%$ Triton X-100 for permeabilization. Non-specific binding was performed by blocking with 5\% BSA (Sigma-Aldrich; Merck KGaA) for $30 \mathrm{~min}$ at $37^{\circ} \mathrm{C}$ and the cells were then incubated with anti-LC3B (1:200; cat. no. L7543; Sigma-Aldrich; Merck KGaA), anti-lysosomal associated membrane protein 2 (LAMP2; 1:200; cat. no. sc-20004; Santa Cruz Biotechnology, Inc.) and anti-YAP (1:200; cat. no. ab52771; Abcam) primary antibodies overnight at $4^{\circ} \mathrm{C}$. Following incubation with the primary antibody, the cells were incubated with an Alexa Fluor 488-conjugated goat anti-rabbit IgG (1:1,000; cat. no. ab150077; Abcam) or an Alexa Fluor 594-conjugated donkey anti-mouse IgG (1:1,000; cat. no. ab150108; Abcam) secondary antibody at room temperature for $1 \mathrm{~h}$. Nuclei were stained with $10 \mathrm{ug} / \mathrm{ml}$ DAPI for $5 \mathrm{~min}$ at $37^{\circ} \mathrm{C}$. The stained cells were visualized using a confocal laser scanning microscope (FV1000; Olympus Corporation).

Cell transfection. Small interfering (si) RNA targeting Atg5 and YAP, and scramble siRNA were synthesized by Shanghai GenePharma Co., Ltd. The sequences of the siRNAs are as follows: Atg5 siRNA, 5'-GCAACUCUGGAUGGGAUU GTT-3'; YAP siRNA, 5'-CGAGAUGAGAGCACAGAC AdTdT-3'; negative control (NC) of Atg5 (siScramble\#1;
5'-GGAAAGAGCUGCAUAUUAATT-3'); and NC of YAP, (siScramble\#2; 5'-UAAGGCUAUGAAGAGAUAC-3'). The SW480 cells were transfected with the siRNAs $(50 \mathrm{nmol} / \mathrm{l})$ at $37^{\circ} \mathrm{C}$ for $48 \mathrm{~h}$ using Lipofectamine ${ }^{\circledR} 3000$ reagent (Invitrogen; Thermo Fisher Scientific, Inc.) according to the manufacturer's protocol. At $72 \mathrm{~h}$ post-transfection, the cells were harvested and used for subsequent experiments.

The pEGFP-LC3 plasmid was kindly gifted by Dr Lu Zhang (Sichuan University, Chengdu, China). The SW480 cells were transfected with the pEGFP-LC3 plasmid $(2.5 \mu \mathrm{g})$ at $37^{\circ} \mathrm{C}$ using Lipofectamine $^{\circledR} 3000$ (Invitrogen; Thermo Fisher Scientific, Inc.) according to the manufacturer's protocol. After $36 \mathrm{~h}$ at $37^{\circ} \mathrm{C}$, the cells were treated with DMSO or TCG $(0.4 \mu \mathrm{M})$ for another $36 \mathrm{~h}$ at $37^{\circ} \mathrm{C}$. Formation of EGFP-LC3 puncta was visualized using fluorescence microscopy (FV1000; Olympus Corporation).

Statistical analysis. Statistical analysis was performed using GraphPad Prism v6.0 software (GraphPad Software, Inc.). Statistical differences between groups were determined using a one-way ANOVA followed by Tukey's post hoc test or an unpaired Student's t-test. The data are presented as the mean $\pm \mathrm{SD}$. $\mathrm{P}<0.05$ was considered to indicate a statistically significant difference.

\section{Results}

TCG inhibits SW480 cell cytotoxicity and proliferation, independent of apoptosis. To determine whether TCG exhibits anticancer effects against colorectal cancer cells, cell viability was determined using a MTT assay. As shown in Fig. 1A, TCG treatment decreased the cytotoxicity of the colorectal cancer cells in a dose-dependent manner compared with that in the control group. Consistent with this finding, the results of the colony formation and BrdU incorporation assays revealed that TCG treatment inhibited SW480 cell proliferation compared with that in the control group (Fig. 1B and C). Furthermore, the LDH release assay showed that TCG treatment increased SW480 cell death compared with that in the control group (Fig. 1D). Taken together, these results indicated that TCG may inhibit SW480 cell proliferation and viability in vitro.

To further evaluate whether apoptosis was associated with the anticancer effect of TCG, the apoptotic ratio was analyzed using flow cytometry. As shown in Fig. 1E, TCG treatment for $24 \mathrm{~h}$ did not significantly increase the levels of apoptosis in SW480 cells compared with that in the control group. Consistent with this observation, the expression levels of cleaved PARP and cleaved caspase- 3 were not altered between TCG-treated and control cells (Fig. 1F). These findings indicated that TCG may not induce apoptosis in the SW480 cell line. Taken together, these data suggested that TCG may inhibit SW480 cell viability and proliferation, independent of apoptosis.

TCG induces autophagy in the SW480 cell line. Accumulating evidence has indicated that autophagy is involved in drug-mediated anticancer therapy $(10,28,29)$; therefore, the present study investigated whether TCG induced autophagy in the SW480 cell line. First, LC3-II accumulation, a hallmark of autophagy, and the levels of Beclin 1 and Atg5, two autophagy-related 

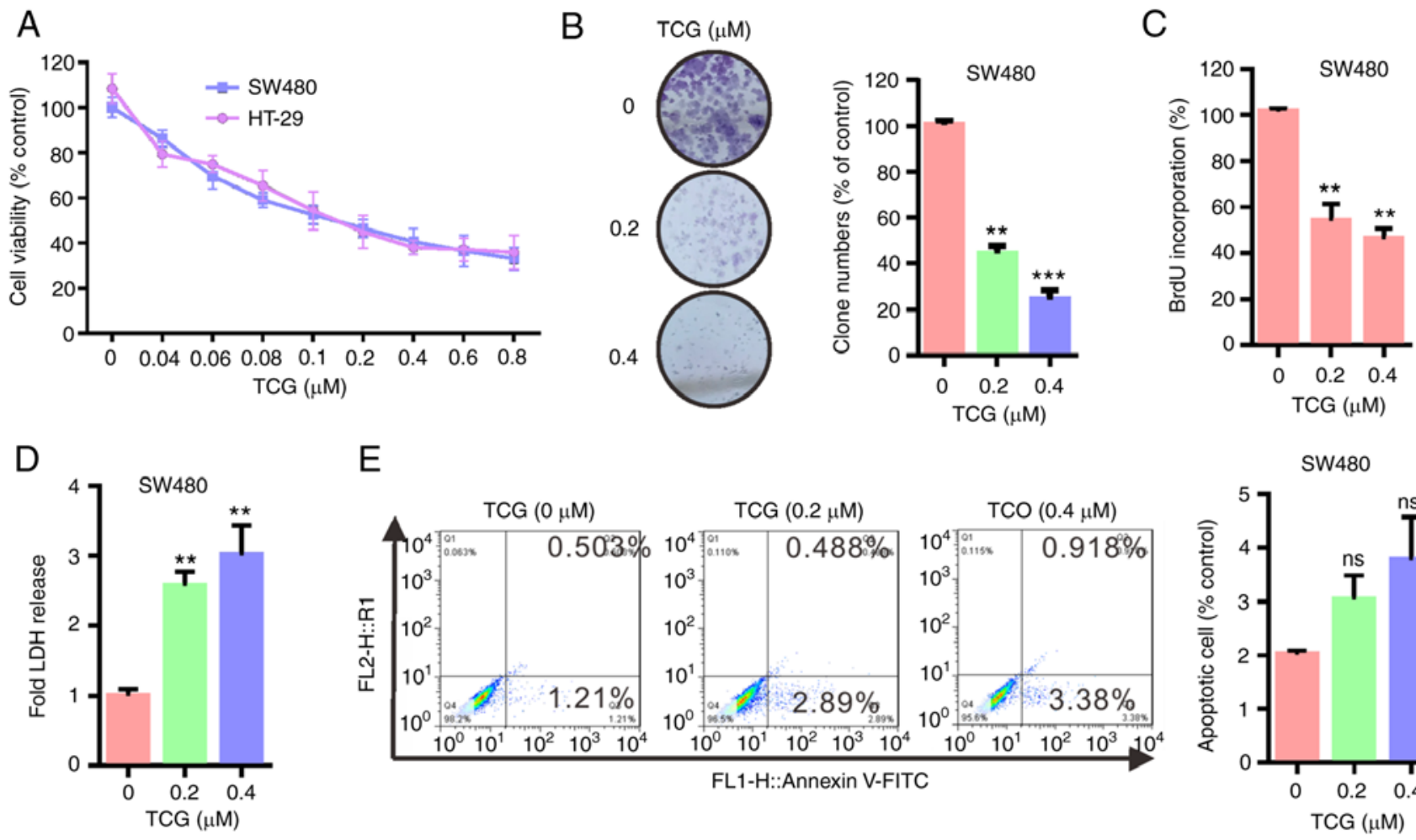

E
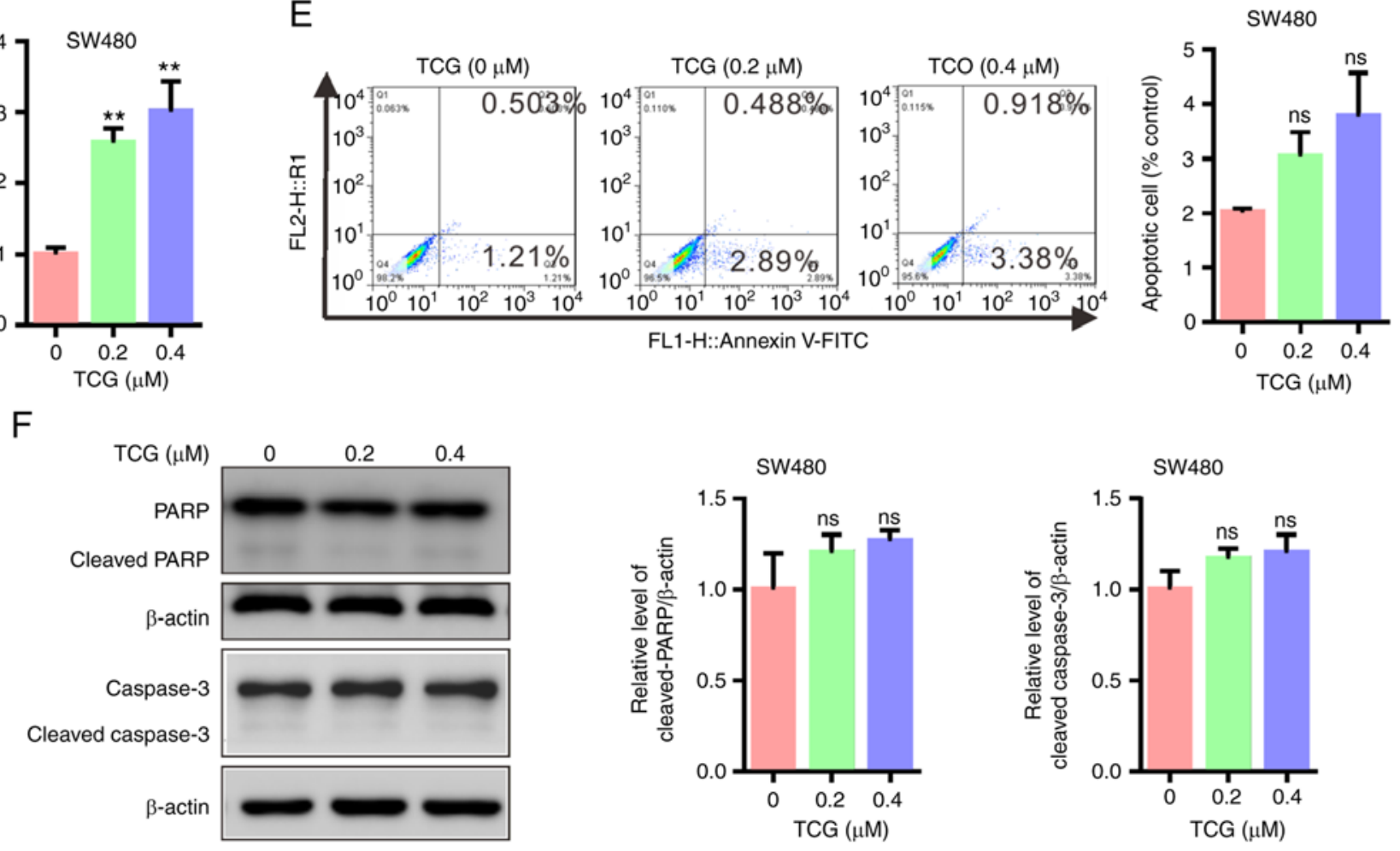

Figure 1. TCG inhibits SW480 cell cytotoxicity and proliferation, which is independent of apoptosis. (A) MTT assay was used to determine the cytotoxicity of cells treated with the indicated concentrations of TCG for $24 \mathrm{~h}$. (B) Colony formation and (C) BrdU incorporation assays were used to determine the proliferation of TCG-treated cells. (D) LDH release assay was performed using the SW480 cell line treated with the indicated concentrations of TCG for $24 \mathrm{~h}$. (E) Apoptosis was analyzed using flow cytometry following AnnexinV-FITC/PI double staining. (F) Western blot analysis was used to analyze the protein expression levels of cleaved PARP and cleaved caspase-3 in the TCG-treated cells, and the protein ratios were calculated following densitometric analysis using ImageJ software. The experiments were repeated in triplicate. ${ }^{* *} \mathrm{P}<0.01,{ }^{* * *} \mathrm{P}<0.001$. TCG, toxicarioside G; BrdU, bromodeoxyuridine; LDH, lactate dehydrogenase; PARP, poly (ADP-ribose) polymerase 1; ns, non-significant.

proteins, were analyzed. As shown in Fig. 2A, TCG treatment markedly increased LC3-II expression in the SW480 cell lines. In addition, the expression levels of Beclin1 and Atg5 were found to be increased in the TCG-treated cells. To confirm this observation, a GFP-tagged LC3B plasmid was used, and a marked increase in GFP-tagged LC3B puncta was observed in TCG-treated cells compared with that in the control cells (Fig. 2B). Next, the distribution of endogenous LC3 puncta, another classical marker of autophagy, was examined. The results revealed that TCG treatment significantly increased the number of endogenous LC3 puncta in the SW480 cell lines (Fig. 2C and D). Furthermore, treatment with 3-MA (an autophagy inhibitor) markedly decreased LC3-II expression in the TCG-treated cells (Fig. 2E). Taken together, these findings indicated that TCG may induce autophagy in SW480 cells.
TCG induces lethal autophagy arrest in the SW480 cell lines. In addition to autophagy initiation, LC3-II accumulation may result from impaired autophagic flux (30). Therefore, the present study investigated whether TCG induced complete autophagic flux in the SW480 cell line. The protein expression levels of LC3-II and P62 (an autophagy-specific substrate) were investigated by adding $\mathrm{CQ}$ (a lysosomal inhibitor) to the TCG-treated cells to CQ. The results revealed that both LC3-II and P62 were significantly increased in TCG-treated cells, but expression was not further increased upon combined treatment with CQ (Fig. 3A). Furthermore, the colocalization of LC3B with LAMP2 (a lysosomal marker) was not observed in the TCG-treated cells (Fig. 3B), suggesting that TCG hinders the fusion of autophagosomes with lysosomes. These results 

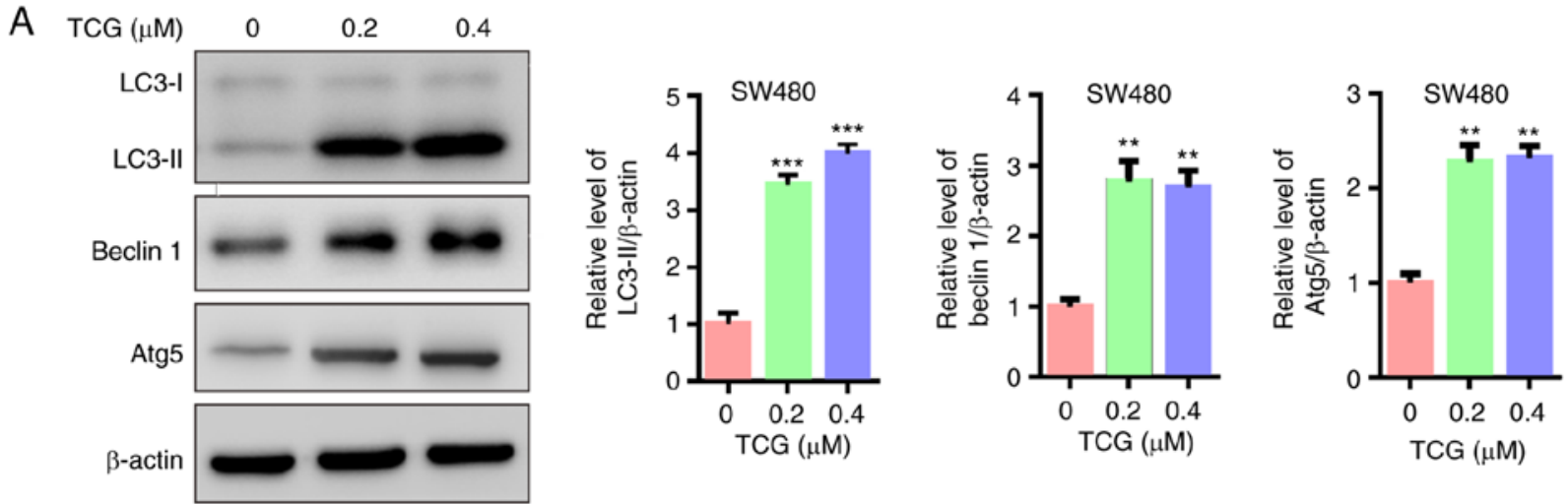

B

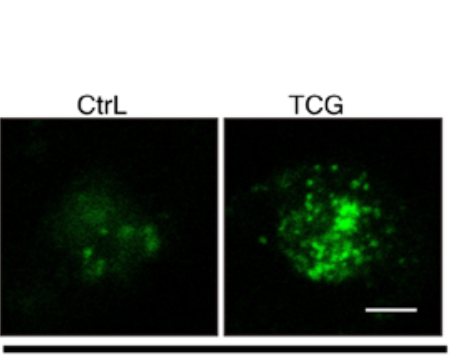

GFP-LC3
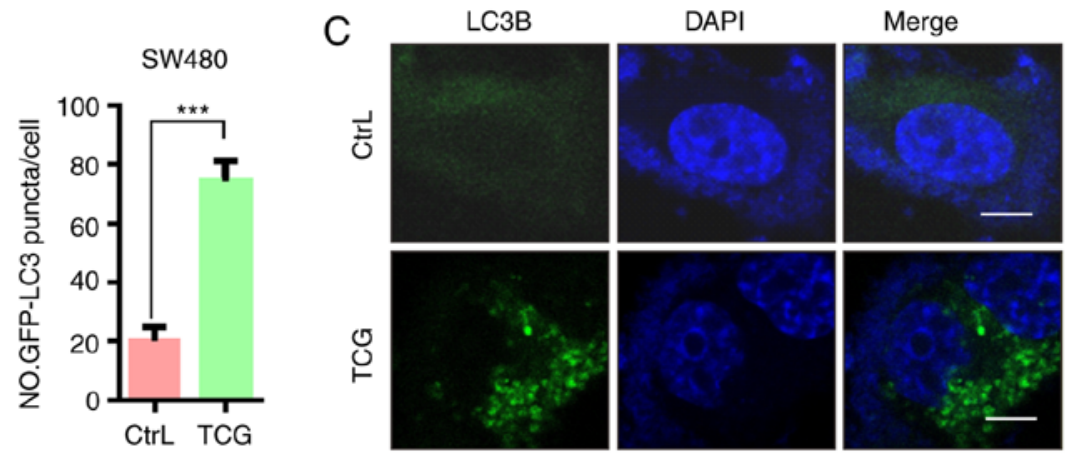

D

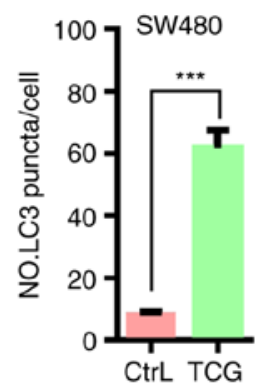

$\mathrm{E}$
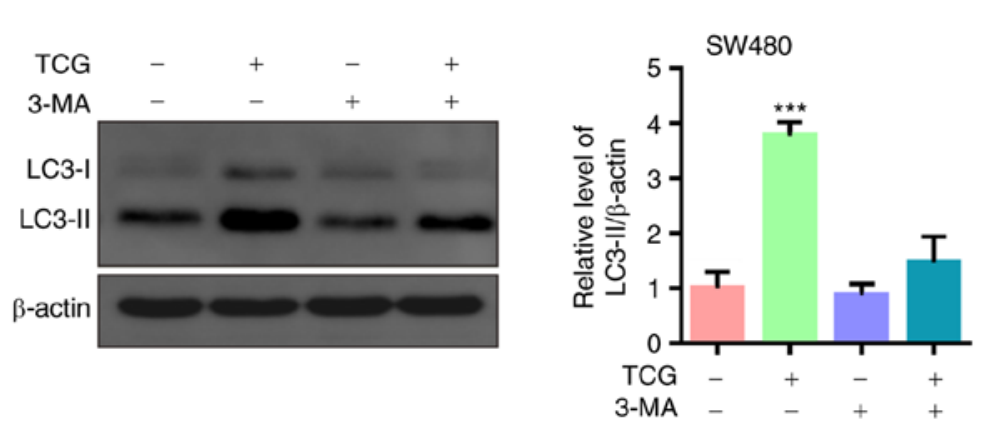

Figure 2. TCG induces autophagy in the SW480 cell line. (A) Western blot analysis was used to analyze the protein expression levels of LC3, Beclin 1 and ATG5 in TCG-treated cells. (B) GFP-tagged LC3B puncta were visualized using a fluorescence microscope. (C) Endogenous LC3 puncta were visualized using a fluorescence microscope and the results were (D) statistically analyzed. (E) Western blot analysis was used to determine the protein expression levels of LC3 in cells treated with TCG and/or in combination with 3-MA. The protein ratios were calculated following densitometric analysis using ImageJ software. The experiments were repeated in triplicate. ${ }^{* *} \mathrm{P}<0.01,{ }^{* * *} \mathrm{P}<0.001$. Scale bar, $10-\mu \mathrm{m}$. TCG, toxicarioside G; ATG5, autophagy related 5; 3-MA, 3-methyladenine; Ctrl, control.

indicated that TCG may induce autophagosome accumulation by blocking autophagosome-lysosome fusion.

To determine whether autophagy was involved in the TCG-mediated inhibition of cell viability and proliferation, the SW480 cell line was treated with TCG in combination with 3-MA or CQ. As shown in Fig. 4A and B, 3-MA treatment markedly restored the TCG-mediated inhibition of cell viability, whereas CQ treatment did not affect cell viability. The results of the BrdU incorporation and colony formation assays showed that 3-MA treatment significantly restored the TCG-mediated suppression of cell proliferation (Fig. 4C and D). In addition, 3-MA treatment markedly decreased TCG-induced cytotoxicity, as evidenced by the LDH release assay (Fig. 4E). Atg5 knockdown significantly decreased Atg5 protein expression levels in the SW480 cell line compared with that in the control group (Fig. 4F and G). Knockdown of Atg5 also prevented the TCG-mediated suppression of cell viability, as evidenced by MTT and LDH release assays (Fig. $4 \mathrm{H}$ and I). Taken together, these results suggested that TCG may inhibit SW480 cell viability and proliferation by promoting lethal autophagosome accumulation.

YAP is activated in TCG-treated SW480 cells. As the Hippo signaling pathway has been found to play a key role in the development of numerous types of human cancer (31), the present study aimed to determine whether the Hippo signaling pathway was associated with the TCG-mediated inhibition of SW480 cell viability and proliferation. The results demonstrated that TCG treatment promoted YAP dephosphorylation at serine 127 in the SW480 cell line (Fig. 5A). In addition, YAP nuclear localization was found to be elevated in the TCG-treated cells (Fig. 5B and C). The mRNA expression levels of downstream target genes of YAP were also investigated. As shown in Fig. 5D, TCG treatment markedly upregulated the mRNA expression levels of CTGF and CCN1. Furthermore, TCG treatment significantly downregulated LATS1 protein expression level in the SW480 cell line (Fig. 5E). Collectively, these results indicated that TCG may 
A

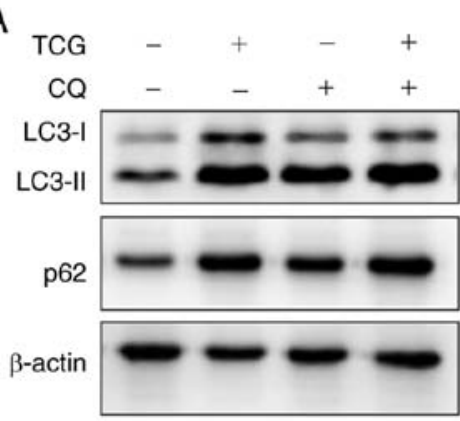

B
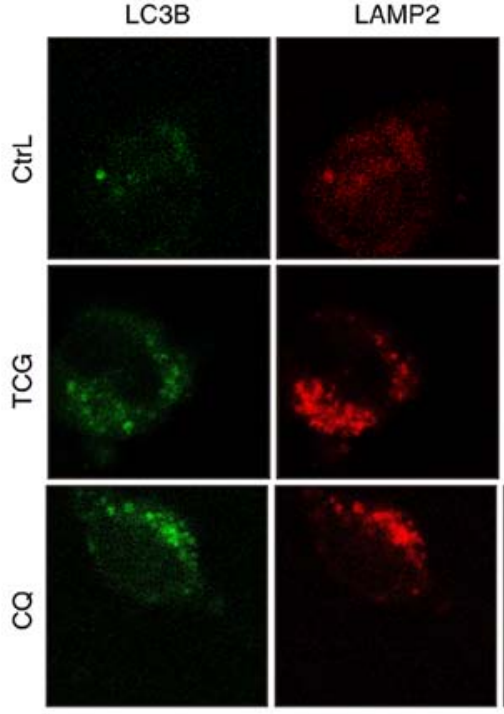
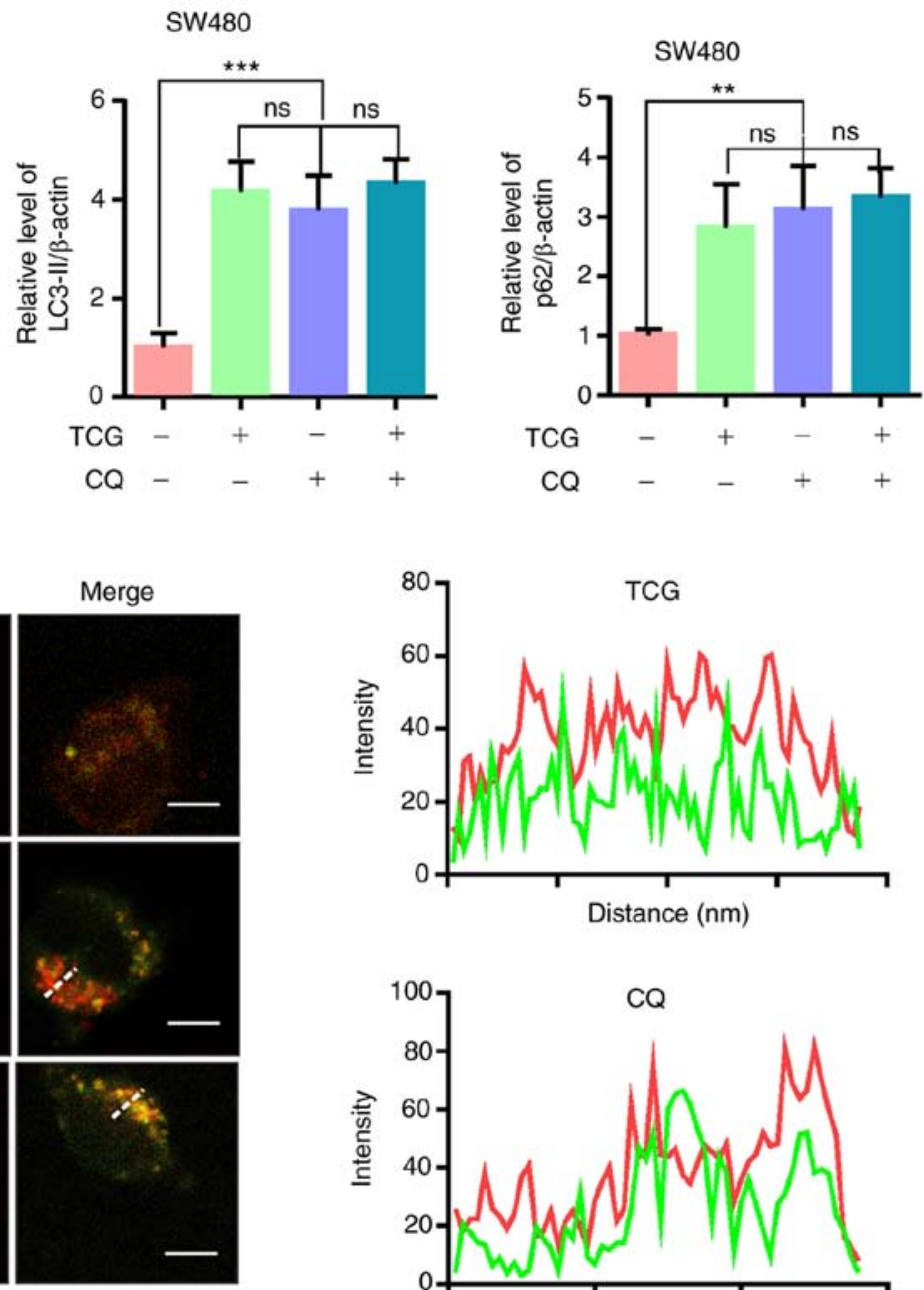
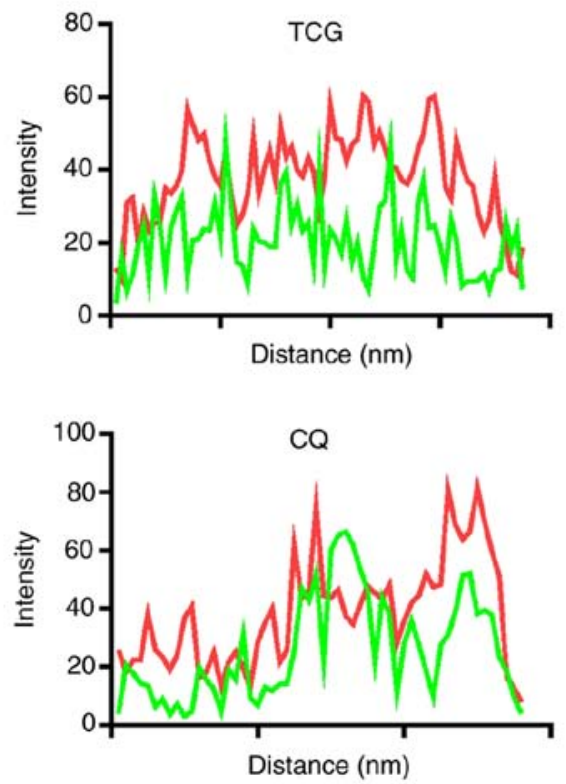

Figure 3. TCG induces autophagosome accumulation in the SW480 cell line. (A) Western blot analysis was used to analyze the protein expression levels of LC3 and P62 in cells treated with TCG in combination with CQ. The protein ratios were calculated following ImageJ densitometric analysis and using Image J software. (B) Immunofluorescent analysis of the colocalization of endogenous LC3B with LAMP2 in cells treated as described in part. (A) Scale bar, 10- $\mu \mathrm{m}$. The experiments were repeated in triplicate. ${ }^{* * *} \mathrm{P}<0.01,{ }^{* * *} \mathrm{P}<0.001$. TCG, toxicarioside G; CQ, chloroquine; LAMP2, lysosomal associated membrane protein 2 ; ns, non-significant; Ctrl, control.

enhance YAP dephosphorylation and nuclear localization, and downstream target gene expression, suggesting that YAP may be activated in the TCG-treated SW480 cell line.

Inhibition of YAP activity enhances the TCG-induced antiproliferative effect in the SW480 cell line. To determine the role of YAP in the TCG-mediated inhibition of cell viability and proliferation, cell viability and proliferation were measured following treatment with the YAP inhibitor, VP. The results of the MTT assay showed that VP treatment significantly decreased cell viability compared with that in cells treated with TCG alone (Fig. 6A). In addition, VP treatment further suppressed cell proliferation in TCG-treated cells, as demonstrated by the BrdU incorporation assay (Fig. 6B). Furthermore, VP treatment markedly increased TCG-induced cytotoxicity, which was evidenced using a LDH release assay (Fig. 6C). YAP knockdown significantly decreased YAP protein expression levels in the SW480 cell line compared with that in the control group (Fig. 6D and E). Knockdown of YAP further enhanced the TCG-mediated inhibition of cell viability and proliferation, which was evidenced by MTT, BrdU incorporation and LDH release assays (Fig. 6F-H).
Taken together, these findings indicated that TCG-induced YAP activation may play a protective role against the TCG-mediated inhibition of cell viability and proliferation.

\section{Discussion}

In recent years, natural products have been of significant interest due to the use of their compounds for medicinal purposes. Numerous natural products derived from plants have exhibited potent anticancer activities and have been successfully used in cancer treatment, such as vincristine, etoposide, irinotecan and paclitaxel (32-34). Cardenolides, a class of natural products, including digitoxin, oleandrin and ouabain, have received considerable attention due to their reported anticancer activities $(1,35,36)$. TCG is a cardenolide isolated from Calotropis gigantea, which has been shown to exert potential anticancer activities in several types of cancer cell line (6). However, to the best of our knowledge, the molecular mechanisms of TCG remain largely unknown. The results of the present study demonstrated that TCG inhibited the viability and proliferation of the SW480 cell line. In 
A

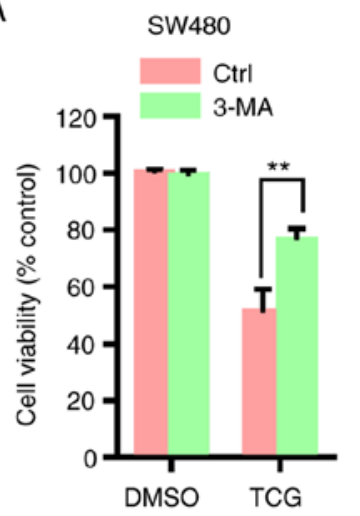

B

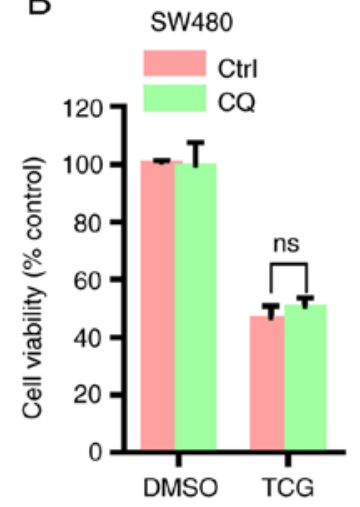

E

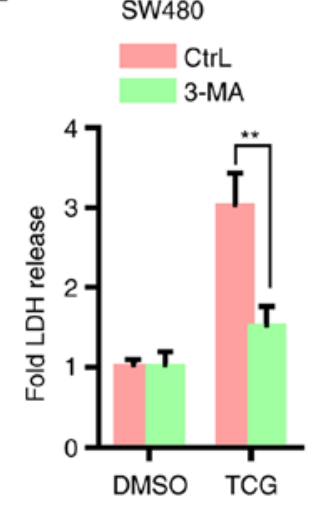

$\mathrm{H}$
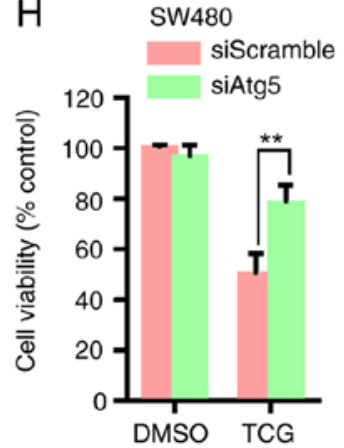

C $\quad$ sw480

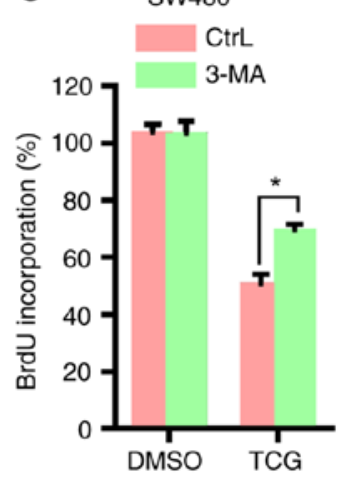

F

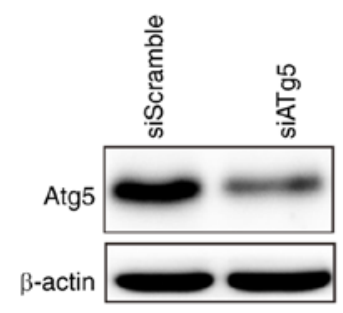

I

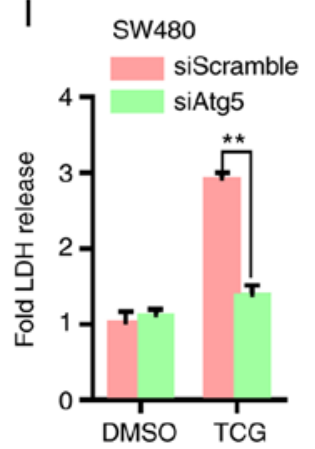

Figure 4. TCG inhibits SW480 cell viability and proliferation by promoting autophagosome accumulation. MTT assay was used to determine the viability of cells treated with DMSO or TCG for $24 \mathrm{~h}$ in the presence or absence of (A) 3-MA or (B) CQ. (C) BrdU incorporation assay was used to determine the proliferation of cells treated as described in part (A). (D) Colony formation assay was used to determine the proliferation of cells treated with DMSO or TCG for 7 days in the presence or absence of 3-MA. (E) LDH release assay was performed using SW480 cells treated as described in part (A). (F and G) Effect of Atg5 knockdown on Atg5 protein expression. (H) MTT assay was used to determine the viability of cells transfected with Atg5 siRNA or siScramble followed by treatment with or without TCG for $24 \mathrm{~h}$. (I) LDH release assay was performed using SW480 cells transfected as described in part. (H) The experiments were repeated in triplicate. ${ }^{*} \mathrm{P}<0.05,{ }^{* *} \mathrm{P}<0.01$. TCG, toxicarioside G; CQ, chloroquine; 3-MA, 3-methyladenine; BrdU, bromodeoxyuridine; LDH, lactate dehydrogenase; si, small interfering; Atg5, autophagy related 5; DMSO, dimethyl sulfoxide; Ctrl, control; ns, non-significant.

addition, TCG induced autophagosome accumulation and the inhibition of autophagy restored the TCG-mediated inhibition of cell viability and proliferation, suggesting that TCG may induce lethal autophagy arrest. The data further showed that TCG induced YAP activation in the SW480 cell line, while the inhibition of YAP activity enhanced the TCG-induced effects on cell viability and proliferation, indicating that YAP may play a protective role in TCG-treated cells.

Accumulating evidence has indicated that autophagy is induced following treatment with numerous anticancer agents $(15,37)$; however, the reported role of autophagy is paradoxical. Some anticancer agents have been shown to induce cytoprotective autophagy and inhibition of autophagy rendered tumor cells vulnerable to these drug treatments $(28,38)$. On the other hand, other anticancer agents were found to induce cytotoxic autophagy and inhibition of autophagy promoted cancer cell proliferation $(17,39)$. The results of the present study revealed that TCG induced autophagy in the SW480 cell line and inhibition of autophagy favored cancer cell proliferation, indicating that TCG may induce cytotoxic autophagy in the SW480 cell line. Autophagy arrest, which is involved in cytotoxic autophagy, has been frequently observed in response to 
A
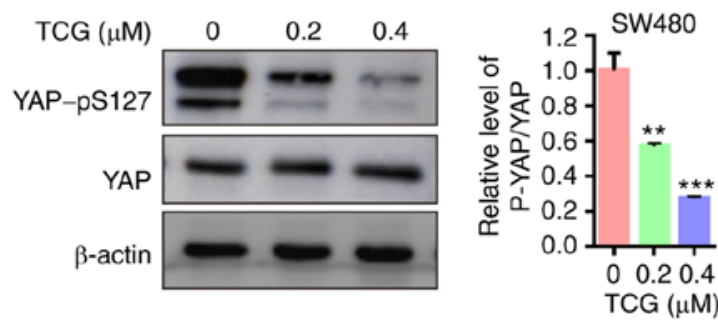

C

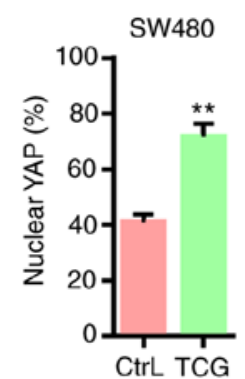

$\mathrm{D}$

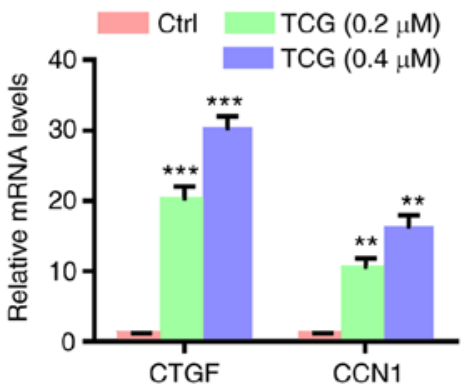

B
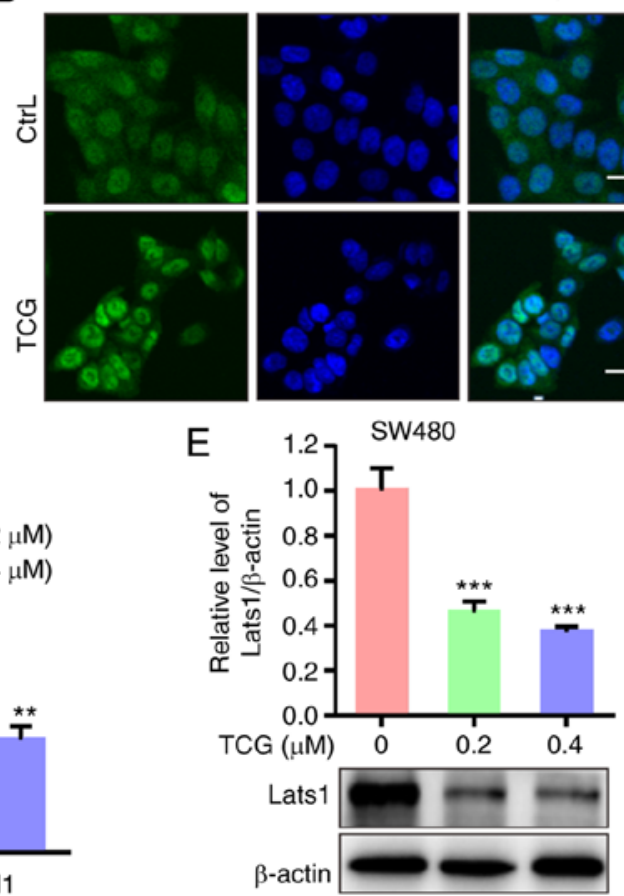

Figure 5. YAP is activated in TCG-treated SW480 cells. (A) Western blot analysis was used to determine the phosphorylation levels of YAP (serine 127) in TCG-treated cells. (B) Immunofluorescent analysis of YAP subcellular localization in TCG-treated cells and the results were (C) statistically analyzed. (D) Reverse transcription-quantitative PCR was used to analyze CTGF and CCN1 mRNA expression levels in TCG-treated cells. (E) Western blot analysis was used to analyze the protein expression levels of LATS1 in TCG-treated cells. The protein ratios were calculated following densitometric analysis using ImageJ software. The experiments were repeated in triplicate. ${ }^{* *} \mathrm{P}<0.01,{ }^{* * *} \mathrm{P}<0.001$. Scale bar, $25-\mu \mathrm{m}$. TCG, toxicarioside G; YAP, Yes1 associated transcriptional regulator; CTGF, cellular communication network factor 2; CCN1, cellular communication network factor 1; LATS1, large tumor suppressor kinase 1; p, phosphorylated; Ctrl, control.

A

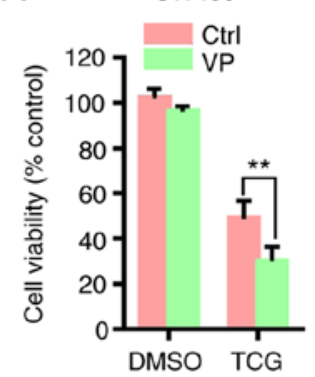

E

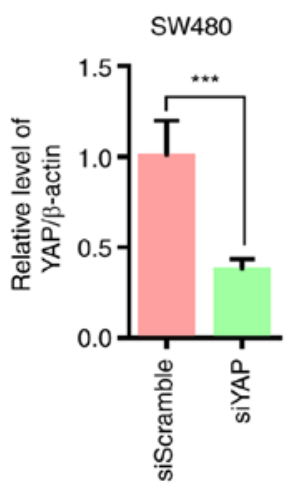

B SW480

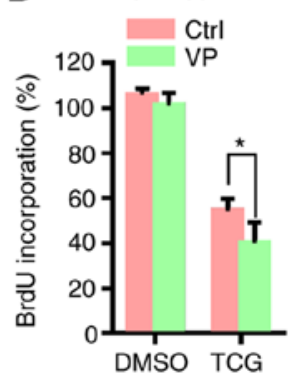

$\mathrm{F}$

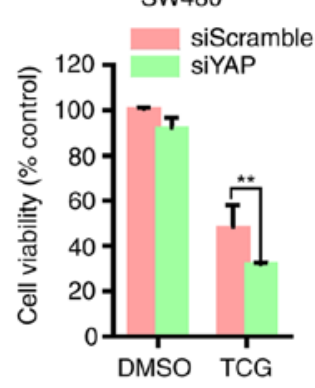

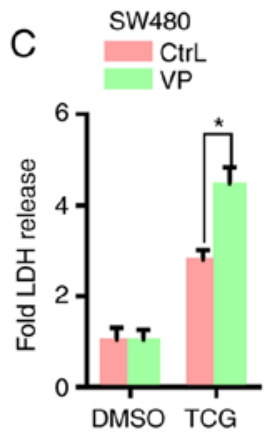

G

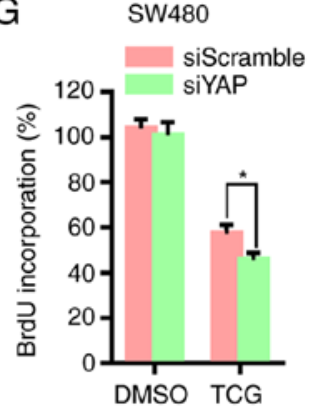

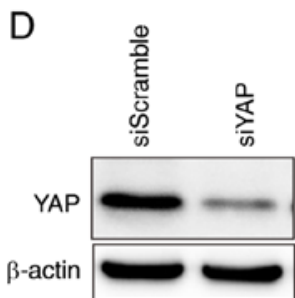

$\mathrm{H}$

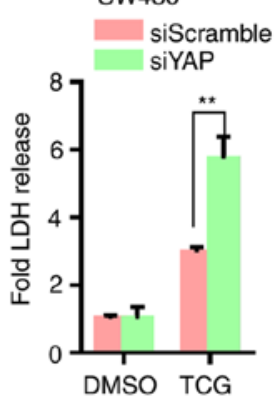

Figure 6. Inhibition of YAP activity enhances TCG-induced lethal autophagosome accumulation in the SW480 cell line. (A) MTT, (B) BrdU incorporation and (C) LDH release assays were used to determine the viability, proliferation and LDH levels in cells treated with DMSO or TCG for $24 \mathrm{~h}$ in the presence or absence of VP. (D) Effect of YAP knockdown on YAP protein expression and the results were (E) statistically analyzed. (F) MTT assay was used to determine the viability of cells transfected with YAP siRNA or siScramble, followed by treatment with or without TCG for $24 \mathrm{~h}$. (G) BrdU incorporation assay was used to determine the proliferation of cells transfected as described in part (F). (H) LDH release assay was performed using SW480 cells transfected as described in part. (F) The experiments were repeated in triplicate. ${ }^{*} \mathrm{P}<0.05,{ }^{* *} \mathrm{P}<0.01,{ }^{* * *} \mathrm{P}<0.001$. YAP, Yes1 associated transcriptional regulator; TCG, toxicarioside G; VP, verteporfin; BrdU, bromodeoxyuridine; LDH, lactate dehydrogenase; si, small interfering; CtrL, control; DMSO, dimethyl sulfoxide. 
chemotherapy. For example, elaiophylin, a natural product, was reported to block the autophagic flux and promote the accumulation of autophagosomes by attenuating lysosomal cathepsin activity, resulting in lethal autophagy arrest (40). Regorafenib, an oral multi-kinase inhibitor, induced lethal autophagy arrest in glioblastoma by inhibiting autophagosome-lysosome fusion (39). Consistent with these observations, the present study demonstrated that TCG induced lethal autophagy arrest in the SW480 cell line by blocking autophagosome-lysosome fusion.

The Hippo signaling pathway plays an important role in regulating numerous aspects of tumor biology, and the dysregulation of the Hippo signaling pathway components has been associated with aberrant cell proliferation and tumor formation $(31,41)$. YAP, a key downstream effector of the Hippo signaling pathway, regulates several context-specific transcriptional programs, and was discovered to promote proliferation and tumor growth $(19,25)$. Amplification of YAP, and high expression levels and nuclear localization, have been frequently observed in numerous types of cancer, including lung, colon and breast cancer, and the abnormal activation of YAP has been associated with tumorigenesis and tumor progression through its ability to act as a powerful tumor promoter $(18,24,25)$. Conversely, in some circumstances, YAP has been discovered to inhibit cell expansion, and also control organ size and growth, which indicated that it may function as a possible tumor suppressor (42). The results of the current study revealed that TCG promoted YAP dephosphorylation, nuclear localization and downstream target gene expression, suggesting that YAP may be activated in the TCG-treated SW480 cell line. The inhibition of YAP activity enhanced the TCG-mediated inhibition of cell viability and proliferation, indicating that YAP activation may play a protective role in TCG-treated cells.

Recently, the emerging link between the Hippo signaling pathway and autophagy has attracted significant attention due to their complex and reciprocal interactions, which have been found to be involved in a wide range of human diseases, including cancer $(43,44)$. Accumulating data have suggested that the Hippo signaling pathway may control autophagy through various mechanisms and the inhibition of YAP function was found to reduce basal autophagy levels $(45,46)$. On the other hand, autophagy has been suggested to regulate the Hippo signaling pathway via numerous different mechanisms. Since YAP acts as an autophagic substrate, the expression levels of the YAP protein and YAP target genes are regulated by autophagy $(47,48)$. The results of the present study demonstrated that TCG induced autophagy, while activating YAP. The findings further revealed that YAP activation restored the inhibited cell viability and proliferation mediated by TCG-induced lethal autophagy arrest in the SW480 cell line.

Admittedly, the present study on TCG-induced autophagy arrest is preliminary and also focuses on the SW480 cell line. Further investigation is required to verify the effect of TCG on autophagy in an additional cell line, to clarify the association between autophagy and the cell cycle, and to perform in vivo experiments.

In conclusion, the findings of the present study suggested that TCG may inhibit SW480 cell proliferation and viability, which may be independent of apoptosis, but associated with autophagy and the Hippo signaling pathway. TCG induced high levels of autophagosome accumulation by blocking autophagosome-lysosome fusion, thereby resulting in lethal autophagy arrest. Furthermore, YAP was found to be activated in the TCG-treated cells and YAP activation attenuated TCG-induced lethal autophagy arrest in the SW480 cell line. These results suggested that TCG may represent a potential anticancer agent for colorectal cancer, and the combined use of YAP inhibitors and TCG may represent a promising strategy for anticancer therapy.

\section{Acknowledgements}

Not applicable.

\section{Funding}

This study was funded by the National Natural Science Foundation of China (grant no. 81860429).

\section{Availability of data and materials}

All datasets generated and/or analyzed during this study are available from the corresponding author upon reasonable request.

\section{Authors' contributions}

LZ and JW designed and performed the experiments, analyzed the data, and drafted the manuscript. JLiu, JLia and YW conducted the experiments and provided the materials for the biological assays. QC and YH conceived the study, supervised all the research and revised the manuscript. All authors contributed to the article and approved the final version. LZ, JW and YH confirm the authenticity of all the raw data.

\section{Ethics approval and consent to participate}

The animal study was reviewed and approved by the Ethics Committee of Hainan Medical University (approval no. HY-2018-1005).

\section{Patient consent for publication}

Not applicable.

\section{Competing interests}

The authors declare that they have no competing interests.

\section{References}

1. Newman RA, Yang P, Pawlus AD and Block KI: Cardiac glycosides as novel cancer therapeutic agents. Mol Interv 8: 36-49, 2008.

2. Cerella C, Dicato M and Diederich $\mathrm{M}$ : Assembling the puzzle of anti-cancer mechanisms triggered by cardiac glycosides. Mitochondrion 13: 225-234, 2013.

3. McConkey DJ, Lin Y, Nutt LK, Ozel HZ and Newman RA: Cardiac glycosides stimulate $\mathrm{Ca}^{2+}$ increases and apoptosis in androgen-independent, metastatic human prostate adenocarcinoma cells. Cancer Res 60: 3807-3812, 2000.

4. Hou Y, Shang C, Meng T and Lou W: Anticancer potential of cardiac glycosides and steroid-azole hybrids. Steroids 171: $108852,2021$. 
5. Skubnik J, Pavlickova V and Rimpelova S: Cardiac glycosides as immune system modulators. Biomolecules 11: 659, 2021.

6. Dai HF, Gan YJ, Que DM, Wu J, Wen ZC and Mei WL: Two new cytotoxic cardenolides from the latex of antiaris toxicaria. J Asian Nat Prod Res 11: 832-837, 2009.

7. Dai HF, Gan YJ, Que DM, Wu J, Wen ZC and Mei WL: A new cytotoxic 19-nor-cardenolide from the latex of antiaris toxicaria. Molecules 14: 3694-3699, 2009.

8. Huang YH, Sun Y, Huang FY, Li YN, Wang CC, Mei WL, Dai HF, Tan GH and Huang C: Toxicarioside O induces protective autophagy in a sirtuin-1-dependent manner in colorectal cancer cells. Oncotarget 8: 52783-52791, 2017.

9. Janku F, McConkey DJ, Hong DS and Kurzrock R: Autophagy as a target for anticancer therapy. Nat Rev Clin Oncol 8: 528-539, 2011.

10. Xia H, Green DR and Zou W: Autophagy in tumour immunity and therapy. Nat Rev Cancer 21: 281-297, 2021.

11. Kroemer G, Marino G and Levine B: Autophagy and the integrated stress response. Mol Cell 40: 280-293, 2010.

12. Rubinsztein DC, Codogno P and Levine B: Autophagy modulation as a potential therapeutic target for diverse diseases. Nat Rev Drug Discov 11: 709-730, 2012.

13. Maes H, Rubio N, Garg AD and Agostinis P: Autophagy: Shaping the tumor microenvironment and therapeutic response. Trends Mol Med 19: 428-446, 2013.

14. Marino G, Niso-Santano M, Baehrecke EH and Kroemer G: Self-consumption: The interplay of autophagy and apoptosis. Nat Rev Mol Cell Biol 15: 81-94, 2014.

15. Shi YH, Ding ZB, Zhou J, Hui B, Shi GM, Ke AW, Wang XY, Dai Z, Peng YF, Gu CY, et al: Targeting autophagy enhances sorafenib lethality for hepatocellular carcinoma via ER stress-related apoptosis. Autophagy 7: 1159-1172, 2011.

16. Elgendy M, Sheridan C, Brumatti G and Martin SJ: Oncogenic Ras-induced expression of Noxa and Beclin-1 promotes autophagic cell death and limits clonogenic survival. Mol Cell 42 23-35, 2011.

17. Dou Q, Chen HN, Wang K, Yuan K, Lei Y, Li K, Lan J, Chen Y, Huang Z, Xie N, et al: Ivermectin induces cytostatic autophagy by blocking the PAK1/akt axis in breast cancer. Cancer Res 76 : 4457-4469, 2016.

18. Yu FX, Zhao B and Guan KL: Hippo pathway in organ size control, tissue homeostasis, and cancer. Cell 163: 811-828, 2015.

19. Zanconato F, Cordenonsi M and Piccolo S: YAP/TAZ at the roots of cancer. Cancer Cell 29: 783-803, 2016.

20. Crunkhorn S: New route to targeting the Hippo pathway. Nat Rev Drug Discov 20: 344, 2021.

21. Meng Z, Moroishi T and Guan KL: Mechanisms of Hippo pathway regulation. Genes Dev 30: 1-17, 2016.

22. Hao Y, Chun A, Cheung K, Rashidi B and Yang X: Tumor suppressor LATS1 is a negative regulator of oncogene YAP. J Biol Chem 283: 5496-5509, 2008.

23. Zhao B, Ye X, Yu J, Li L, Li W, Li S, Yu J, Lin JD, Wang CY, Chinnaiyan AM, et al: TEAD mediates YAP-dependent gene induction and growth control. Genes Dev 22: 1962-1971, 2008.

24. Cottini F, Hideshima T, Xu C, Sattler M, Dori M, Agnelli L, ten Hacken E, Bertilaccio MT, Antonini E, Neri A, et al: Rescue of Hippo coactivator YAP1 triggers DNA damage-induced apoptosis in hematological cancers. Nat Med 20: 599-606, 2014.

25. Avruch J, Zhou D and Bardeesy N: YAP oncogene overexpression supercharges colon cancer proliferation. Cell Cycle 11: 1090-1096, 2012.

26. Zhao B, Li L, Lei Q and Guan KL: The Hippo-YAP pathway in organ size control and tumorigenesis: An updated version. Genes Dev 24: 862-874, 2010.

27. Livak KJ and Schmittgen TD: Analysis of relative gene expression data using real-time quantitative PCR and the 2(-Delta Delta C(T)) method. Methods 25: 402-408, 2001.

28. Yang PM, Liu YL, Lin YC, Shun CT, Wu MS and Chen CC: Inhibition of autophagy enhances anticancer effects of atorvastatin in digestive malignancies. Cancer Res 70: 7699-7709, 2010.
29. Limpert AS, Lambert LJ, Bakas NA, Bata N, Brun SN, Shaw RJ and Cosford NDP: Autophagy in cancer: Regulation by small molecules. Trends Pharmacol Sci 39: 1021-1032, 2018.

30. Klionsky DJ, Abdalla FC, Abeliovich H, Abraham RT, Acevedo-Arozena A, Adeli K, Agholme L, Agnello M, Agostinis P, Aguirre-Ghiso JA, et al: Guidelines for the use and interpretation of assays for monitoring autophagy. Autophagy 8: 445-544, 2012.

31. Harvey KF, Zhang X and Thomas DM: The Hippo pathway and human cancer. Nat Rev Cancer 13: 246-257, 2013.

32. Gordaliza M: Natural products as leads to anticancer drugs. Clin Transl Oncol 9: 767-776, 2007.

33. Koehn FE and Carter GT: The evolving role of natural products in drug discovery. Nat Rev Drug Discov 4: 206-220, 2005.

34. Mishra BB and Tiwari VK: Natural products: An evolving role in future drug discovery. Eur J Med Chem 46: 4769-4807, 2011.

35. Prassas I and Diamandis EP: Novel therapeutic applications of cardiac glycosides. Nat Rev Drug Discov 7: 926-935, 2008.

36. Maoyuan YW, Wenli M, Yuanyuan D, Shenglan L, Zhunian W and Haofu D: Cytotoxic cardenolides from the roots of Calotropis gigantea. Modern Pharm Res 1: 4-9, 2008.

37. Wang K, Liu R, Li J, Mao J, Lei Y, Wu J, Zeng J, Zhang T, Wu H, Chen L, et al: Quercetin induces protective autophagy in gastric cancer cells: Involvement of Akt-mTOR- and hypoxia-induced factor 1 $\alpha$-mediated signaling. Autophagy 7: 966-978, 2011.

38. Liu R, Li J, Zhang T, Zou L, Chen Y, Wang K, Lei Y, Yuan K, Li Y, Lan J, et al: Itraconazole suppresses the growth of glioblastoma through induction of autophagy: Involvement of abnormal cholesterol trafficking. Autophagy 10: 1241-1255, 2014.

39. Jiang J, Zhang L, Chen H, Lei Y, Zhang T, Wang Y, Jin P, Lan J, Zhou L, Huang Z, et al: Regorafenib induces lethal autophagy arrest by stabilizing PSAT1 in glioblastoma. Autophagy 16: 106-122, 2020

40. Zhao X, Fang Y, Yang Y, Qin Y, Wu P, Wang T, Lai H, Meng L, Wang D, Zheng Z, et al: Elaiophylin, a novel autophagy inhibitor, exerts antitumor activity as a single agent in ovarian cancer cells. Autophagy 11: 1849-1863, 2015.

41. Yu FX, Luo J, Mo JS, Liu G, Kim YC, Meng Z, Zhao L, Peyman G, Ouyang $\mathrm{H}$, Jiang W, et al: Mutant Gq/11 promote uveal melanoma tumorigenesis by activating YAP. Cancer Cell 25: 822-830, 2014.

42. Barry ER, Morikawa T, Butler BL, Shrestha K, de la Rosa R, Yan KS, Fuchs CS, Magness ST, Smits R, Ogino S, et al: Restriction of intestinal stem cell expansion and the regenerative response by YAP. Nature 493: 106-110, 2013.

43. Wang D, He J, Huang B, Liu S, Zhu H and Xu T: Emerging role of the Hippo pathway in autophagy. Cell Death Dis 11: 880, 2020.

44. Tang F and Christofori G: The cross-talk between the Hippo signaling pathway and autophagy:Implications on physiology and cancer. Cell Cycle 19: 2563-2572, 2020.

45. Totaro A, Zhuang Q, Panciera T, Battilana G, Azzolin L, Brumana G, Gandin A, Brusatin G, Cordenonsi M and Piccolo S: Cell phenotypic plasticity requires autophagic flux driven by YAP/TAZ mechanotransduction. Proc Natl Acad Sci USA 116: 17848-17857, 2019

46. Tang F and Christofori G: LATS1-Beclin1 mediates a non-canonical connection between the Hippo pathway and autophagy. Mol Cell Oncol 7: 1757378, 2020.

47. Lee YA, Noon LA, Akat KM, Ybanez MD, Lee TF, Berres ML, Fujiwara N, Goossens N, Chou HI, Parvin-Nejad FP, et al: Autophagy is a gatekeeper of hepatic differentiation and carcinogenesis by controlling the degradation of Yap. Nat Commun 9: 4962, 2018.

48. Zhou Y, Wang Y, Zhou W, Chen T, Wu Q, Chutturghoon VK, Lin B, Geng L, Yang Z, Zhou L and Zheng S: YAP promotes multi-drug resistance and inhibits autophagy-related cell death in hepatocellular carcinoma via the RAC1-ROS-mTOR pathway. Cancer Cell Int 19: 179, 2019.

This work is licensed under a Creative Commons Attribution-NonCommercial-NoDerivatives 4.0 International (CC BY-NC-ND 4.0) License. 